African Journal of Educational Studies in Mathematics and Sciences Vol. 7, 2009

\title{
Developing a Geographic Information System (GIS) application for soils and crop suitability studies in Atwima District of Ghana
}

\author{
Owusu-Akyaw, K. B. ${ }^{10}$
}

\section{Abstract}

This paper reports a study that sought to develop a Geographic Information System (GIS) application for soils and their crops suitability in the Atwima District. The purpose of the study was to digitally capture, store, and analyze the soil map and crops suitability data of the district. GIS is a computer-based system for gathering, storing, manipulating and analyzing spatial data to support decision making. In this study, the soil map of the Atwima district was digitized and analyzed with GIS software called ArcView. The soil characteristics and crops suitability data were also added in tabular form to the database. A thematic map showing soil associations and their crop suitability was then generated from the database and displayed concurrently with the tabular data. Analysis of the map and table proved that it is easier to study soils and their suitable crops from their data displayed concurrently on the desktop. It was therefore concluded that developing GIS application for the study of soils and crops suitability is an effective way of bringing all related datasets together to support agricultural research and decision making. The main recommendation was that agricultural students must develop a comprehensive GIS database that will include all datasets relevant to soils and crops studies and management.

Keywords: $\quad$ geographic information system, digitalized soil map, soils and crops studies

\section{Introduction}

According to Adjei-Gyapong and Asiamah (1998), soil mapping, classification and evaluation began in Ghana in 1946 by the Soil Research Institute (SRI) of Ghana. The soil map is at a scale of 1:250000 and covers the whole country. Soil maps at the scale of 1:100000 covering the districts are also available. The soils on the district maps are grouped into associations of soil series and are described in greater detail. Asiamah (1999) added that the soil series concepts are well embraced by local soil scientists because they make soil mapping rather easy. However, he stated that the difficulty noted by the scientists was that there were too many soil series because they were defined mainly by their forming factors. This has made young soil scientists and students unable to identify soils in the field easily, when they use the existing soil association series map with wide range of characteristics of some of the series, coupled with changes that occur over time.

Since the 1970s, nearly all soil series dug, described, sampled and analyzed in Ghana by the SRI have been classified in at least one international soil classification system, especially the

\footnotetext{
${ }^{10}$ Owusu-Akyaw, K. B lectures at the Design and Technology Education Department, University of Education Winneba, located at the Kumasi Campus in Ghana.
} 
Developing a Geographic Information System (GIS) application for soils and crop suitability studies in Atwima District of Ghana

Owusu-Akyaw, K. B.

FAO/UNESCO Soil Map of the World Revised Legend (FAO, 1988). According to the Food and Agricultural Organization (FAO ,1998) the system of classification is old and does not incorporate latest findings in soil research and therefore must be operated around the pivot of a universally accepted system, which is the World Reference Base for soil resources (WRB). Currently they have therefore increasingly used Remote Sensing (RS) technology as an important and major source of geographic information on soils, land cover and land use needed for rational development and sustainable management of agricultural and environmental protection in its programmes and field projects. Remote sensing is the use of aerial photography and satellite imagery to capture spatial data as input into GIS. The ultimate criteria for the measure of RS and GIS are the extents to which they contribute to the quality of life, especially, in agricultural-based economies.

The FAO in collaboration with the SRI therefore co-sponsored the digitization of Ghana's soil maps. They have also separately produced Digital Elevation Model (DEM), Land Suitability, and Cropping Systems maps. Currently, the SRI is selling these digital maps as separate files but at discount for educational institution. Though these maps serve as basis for further research, they are not integrated into a composite map comprising of all relevant topographic and demographic data. They also do not have attribute data in tabular form and not interactive enough to aid updating and further studies. Table 1 below is an extract of the digital soil suitability maps for sale at the SRI.

Table 1 Cost of districts' digital soil maps

\begin{tabular}{lllll}
\hline District & Soil Map & Land Suitability (single/multiple crop) & DEM/Slope & Cropping Systems \\
\hline & $\$ 80$ & $\$ 120$ & $\$ 200$ & $\$ 10$ \\
\hline
\end{tabular}

Darrell Schulze (2008) has taught his students at Purdue University in Indiana to visualize soils and landscapes with GIS. The students use GIS in the classroom and in the field to better understand soils and landscapes and to recognize geologic features that indicate different soil types. Soil classification, genesis, and survey classes incorporate GIS software to study the relationships between soils, topography, land use, and geology. The teacher uses GIS to share data with the students, who in turn use it to observe different points in the landscape. He continued, "At the beginning of the class, most students know little about geography and GIS, but by the time they complete the course, they are able to access geographic data and view it with GIS tools. Newly released data, map products, and models continue to advance with each new class". Schulze is currently working on an application in which students can click a polygon to query the attribute table, as well as click a link that leads them to a schematic diagram of a soil profile that illustrates what the soil looks like below the surface.

Schulze explains that two approaches can be taken in using GIS for education. One is teaching about GIS and how it works, and the other is using GIS to teach particular concepts. In the latter, he continues, teachers design maps for students, working them into a format that works well for the specific class. The data is preassembled and put into a format that works easily for the student and helps the teacher focus precisely on the topic. Hands-on use of GIS-loaded Laptop PCs reinforces concepts from the lecture. He concluded 'GIS is helping us teach concepts in our class that would otherwise take students years of field experience to acquire."

Broten (2002) also shared his experience that an Arc View-based application has been developed in Bangladesh to combine national associations map with digital elevations maps, and the system 
also includes crops suitability and soils physical characteristics. Arc View is therefore versatile desktop decision-support GIS software for the capture, storage, management and analysis of spatial data. Meulen (1998) also rightly stated that the use of desktop GIS software called Arc view makes it easy to store, retrieve and view soil suitability data with data on other subjects such as land use and crop suitability, land elevation, hydrology, forest reserves, road networks, hydrology and social amenities which all contribute to agricultural production. They also help in taking informed decision on site specific issues on soils and agriculture.

The objectives of this study were therefore to:

- Create digital, development and soil maps of Atwima district for soil studies.

- Create relevant attribute data to the soil map in tabular form.

- Generate composite and thematic maps for analysis.

To achieve these objectives the research sought to find answers to the following questions:

- How can topographic and development maps of the district be integrated into its soil map and crops suitability data?

- What are the benefits of adding attribute data to the district's soil map?

This study is significant to faculties and students of agricultural institutions and soil researchers; in that they can use it as a model to create their own comprehensive soil maps and generate thematic maps from them for teaching and learning and for soil research. Muhammad Sabir (2006) has confirmed this in his statement 'The GIS is being used for agricultural resources management on sustainable basis. It makes soil management less tedious and less costly by collecting a wider spectrum of data in a short time'. However the views of Brooker and Gray (1990) is that GIS analysis has yet to see extensive use in agriculture, but is well suited to the site-specific nature of agricultural production decisions. Tomlinson (1990) adds that Decisions about crop choices typically depend on soil characteristics, climatic conditions, distance to markets, equipment availability, and relation of labour needs to labour availability, factors which all have geographic dimension and require GIS to analyze.

\section{Materials and Methods}

The study was conducted from the year 2000 to 2002 in the Atwima District. During this time the countrywide digitization of Ghana soil maps was been undertaken by the SRI under the sponsorship of the FAO. The district shares boundary with the Kumasi Metropolis and is vegetated by semi-deciduous rain forest. Currently, after the study, it has been divided into two Atwima Nwabiagya and Atwima Mponua.

The soil map of the Atwima district at the scale of 1:100000 was collected from the SRI in Kumasi. The legend on the map included the characteristics and crops suitability of the soil associations. The district's development map at the scale of 1:100000 was also collected from the district assembly. The map showed settlements, roads, hydrology, forest reserves and contours. The digital topographic map of the district was also collected from the Survey Department, Accra. The soils and development maps of the district were digitized separately using a Calcomp AO digitizer and GIS software called Arc Info. A topology was then generated for the soil map in the Arc Info environment to create a table which referenced the map features to the tabular keys. These digital maps and the topological table were exported into Arc View environment for editing. Attribute data was then added to the soil map by creating a table of soil associations with their characteristics (or descriptions) and suitable crops. The soil map was then 
Developing a Geographic Information System (GIS) application for soils and crop suitability studies in Atwima District of Ghana

Owusu-Akyaw, K. B.

super imposed on the development map in order to add features on the latter to the former. The resulting soil map was then super imposed on the digital topographic map of the district to check accuracy of the digitized maps, and this was found to be within acceptable limit of 0.005 .

\section{Results and Discussion}

The soil associations have been represented on the table as polygons with one identification (id) number for associations with the same name, as shown in Figure 1.

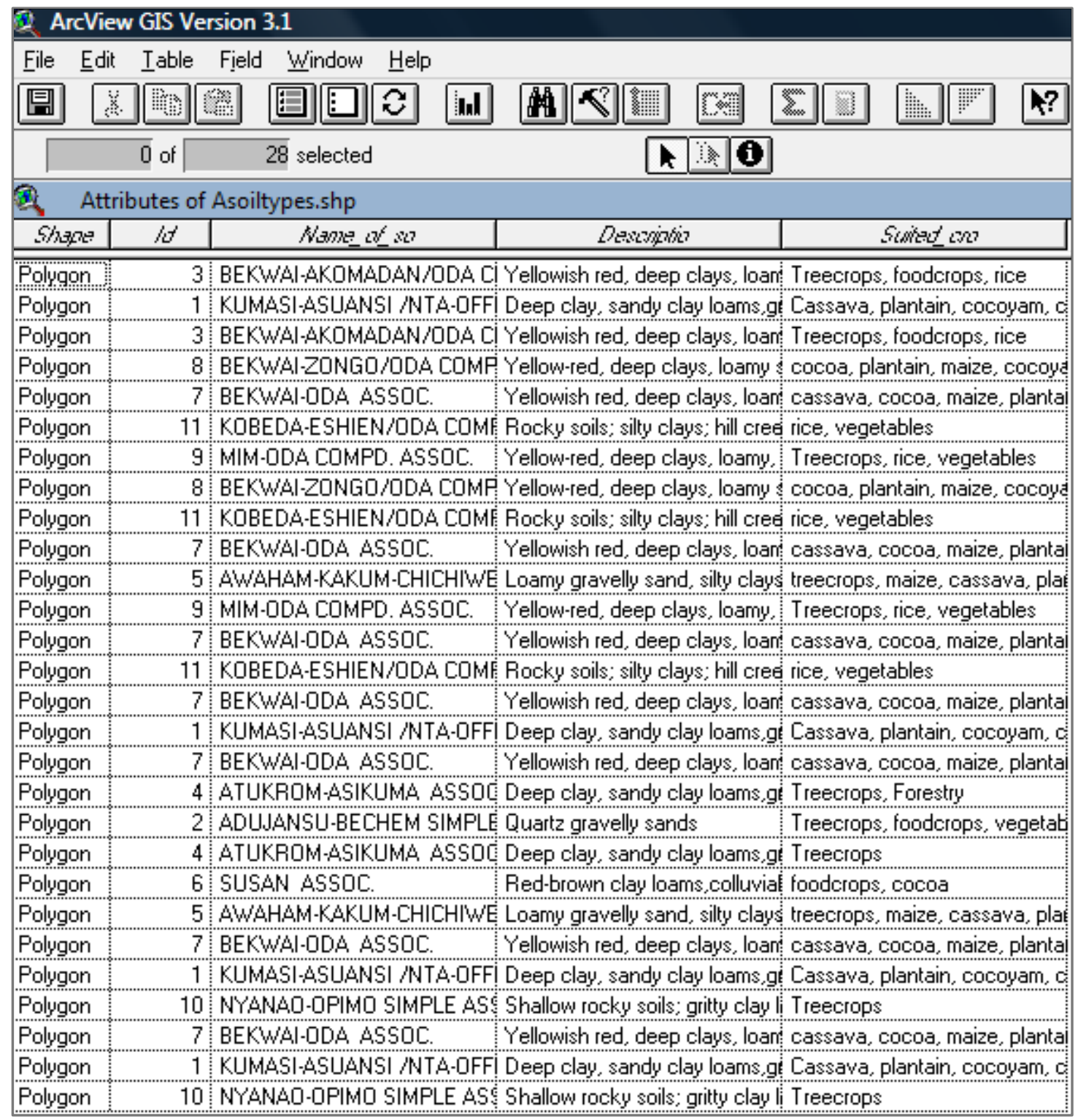

Figure 1 Topological table of Atwima district soil attributes captured from GIS

The soil associations have also been drawn as polygons on the map. Figure 1 shows the names of eleven different associations. It also indicates the different colours and patterns that have been used to distinguish them. There are twenty-eight land parcels and each belongs to one of these 
eleven associations. One or more major towns have also been indicated in each association in order to better identify the location of the association. Demographic data of the towns has been entered into the database and used for crop production analysis, but such analysis is beyond the scope of this paper. Most of the soils are described as red and deep clay. All the soil association support food crops except two - Nyamoa-Opimo single association and Atukrom-Asikuma association - which support tree crops.

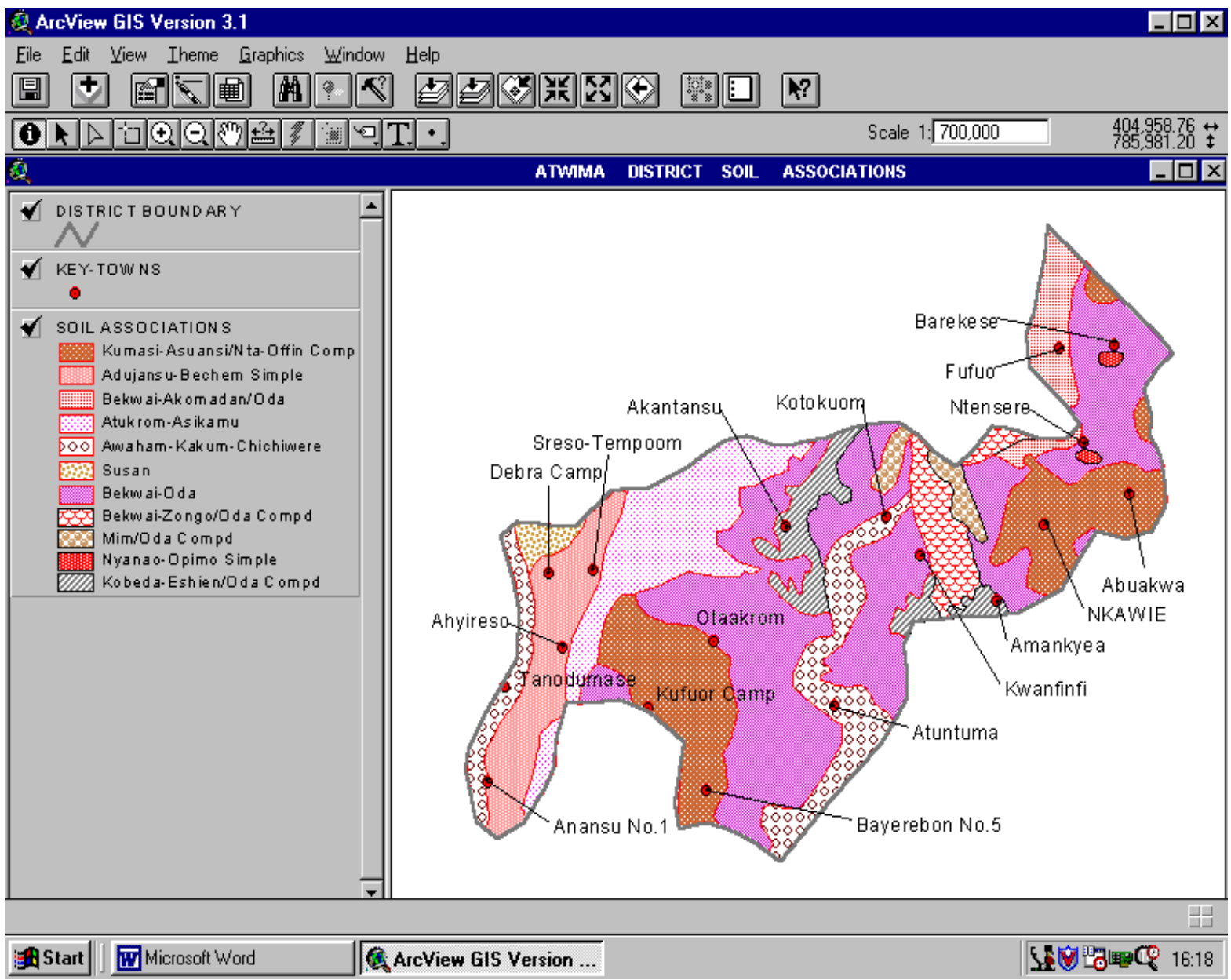

Figure 2 Soil associations and towns located in them

This study has solved the inherent inconvenience of using the map and separate data table since both are combined into one GIS layer, as in Figure 2. 
Developing a Geographic Information System (GIS) application for soils and crop suitability studies in Atwima District of Ghana

Owusu-Akyaw, K. B.

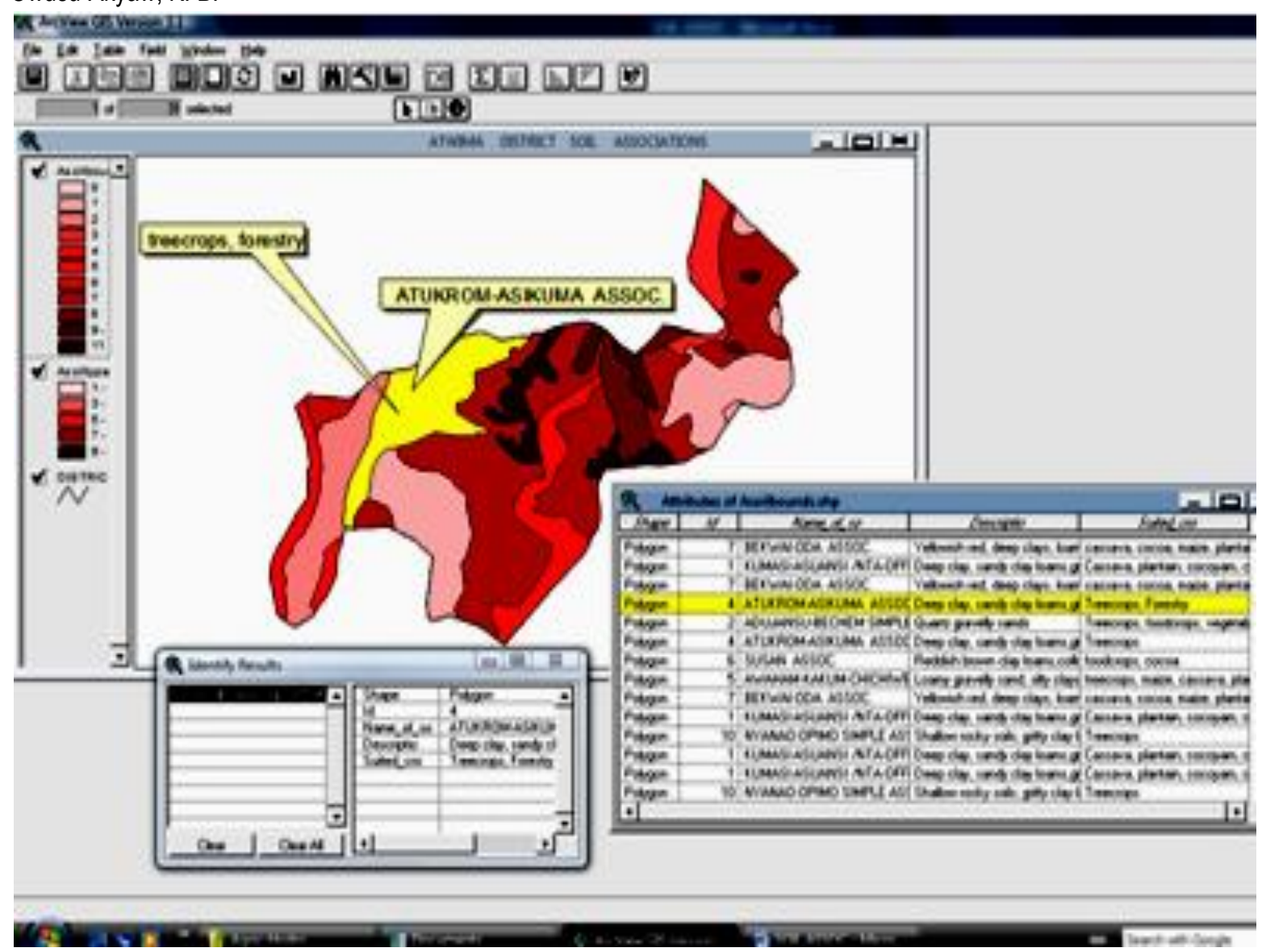

Figure

Concurrent display of Atwima district soil map and attribute tables

The concurrent display of thematic soil map and attribute table has revealed trends otherwise hidden in the attribute table for visual analysis and desktop decision support. This has been demonstrated by the "call out' labels in figure 2. Moreover the 'called out' function of Arc View was used to display on the map suitable crops for selected soil series, as in the case of BekwaiOda series having rice and vegetables as suitable crops. This made visual analysis very easy, straight forward, and interactive. The Identify function of Arc View has also been used to interactively identify soil polygons on the map, as shown by the identify table shown as insert on the map. When a soil association was selected on the map with the Identify function of the Arc View, its name was highlighted on the attribute table, and its corresponding attribute data set was automatically displayed on the insert table as in figure 2, where the Adujansu-Bechem series has been selected. Muhammed Sabir (2006) supports this analogy in his statement "The GIS assist in identifying and handling issues important to the studying and strengthening of farming practices, can improve the understanding and analysis of farming areas, and help promote agricultural research and development". From figure 2, it can also be seen that the larger portion of the land is formed by the Bekwai-Oda soil association and is suitable for food crops like cassava, plantain and maize.

Concerning the use of soils or land, it can be seen that cocoa is the most suitable crop for most portions of the land though alternative crops like food crops are also suitable for the same 
portions. This confirms what Myers (1993) said that, an alternative crop GIS can allow an innovative student or farmer to more accurately determine appropriate alternative crops for his or her farm, without necessarily having to wait for field research to be conducted in his or her region. According to him, maps indicating the most suitable regions for selected alternative crops can also be useful for siting field research studies. Although the prototype soil and crop suitability maps above appear to provide useful information on crop production, there are other factors that should be considered and incorporated into the GIS for better evaluation of suitability. The factors include the role of transportation, labour available for farms, availability of markets, hydrology and land use.

\section{Conclusion}

In this study, the use of GIS in the digital mapping of soils, settlements and their attributes in the Atwima district has been used to develop a comprehensive database which can be used for soils and crop suitability education and research. The concurrent display of the soil associations' map with their characteristics, crop suitability and all relevant attribute data sets has also aided visual analysis and decisions-making on soils and alternative crop choices. The study has therefore shown that it is therefore not enough to produce separate soils and cropping systems maps with GIS. Rather attribute databases must also be created for further interactive studies, research, updating and critical analyses. For soil and crop suitability studies, GIS has been demonstrated to be an effective tool through the concurrent display of soils, their characteristics, crops and settlements on one composite map. The suitability maps generated in this study will be used to site future field research with food crops and cocoa, and to help industries and farmers determine the best land parcels for selected crop production.

\section{Recommendations}

Based on the results and conclusion of the study, the following recommendations are made:

(1) The Atwima district authorities must use the database developed out of this research to help improve agriculture services delivery and also to update it to include current demographic data of the district.

(2) The Soil Research Institute must make the digital soil maps more affordable and accessible to agricultural institutions so that students can help to create more thematic maps from them. This is because database development calls for a lot of hands and supervision which the agricultural institutions can provide at minimal cost to the nation.

(3) The Ministry of Food and Agriculture must ensure that agricultural stakeholders put resources together to develop a common GIS database that would include all datasets relevant to soil management and crop production and studies.

(4) Agricultural institutions must develop GIS applications for their soils and crops education and research. Students must be involved in developing and updating the comprehensive databases so that they can use them interactively. 
Developing a Geographic Information System (GIS) application for soils and crop suitability studies in Atwima District of Ghana

Owusu-Akyaw, K. B.

\section{References}

Adjei-Gyapong, T. and Asiamah R. D (1998) The interim Ghana soil classification system and its relation with the world Reference Base for Soil Resources. Kumasi: Soil Research Institute, Kwadaso, Kumasi

Asiamah, R.D. (1999) Plinthite and conditions for its hardening in agricultural soils in Ghana. Kumasi: Soil Research Institute, Kwadaso, Kumasi

Brooker, J.R. and Gray, M.D. (1990) Identification of vegetable growing areas in Tennessee from computer-generated maps based on geographic information systems. Tennessee Farm and Home Science, Number 153, Winter 1990, Univ. Tennessee Agr. Expt. Sta.

Broten, (2002) Bangladesh establishes a GIS-Based Agricultural and Land Resources Information System, ArcNews ESRI, Spring 2000 Vol.22 No.1, California, USA

Darrell Schulze (2008) Purdue University Students Visualize Soils and Landscapes with GIS, ArcNews Online Summer 2008, www.esri.com

Food and Agriculture Organization (1988) FAO/UNESCO Soil Map of the World Revised Legend, www.fao.org

Meulen, M. V. D. (1998) NAZCA: the soil information system for soil quality management, CSO Consultants for Environmental Management and Survey, Regulierenring 20, 3981 LB Bunnik, The Netherlands

Muhammed Sabir (2006) Geographic information system in reshaping agriculture, DAWN the internet Edition, http//DAWN.com

Myers, R. L. (1993) Determining amaranth and canola suitability in Missouri through Geographic Information Systems analysis Pg 102-105 In: J. Janick and J.E. Simon (eds.), New crops. Wiley, New York

Tomlinson, R. F (1990) Geographic information System - a new frontier, In; O.J Peuquet and D.F. Marble (eds). Introductory readings in geographic information systems, Taylor and Francis, New York 